\title{
Exploring process 'verbs' in EFL postgraduates' citations: A Systemic Functional Linguistics approach
}

\author{
Nayef Jomaa Jomaa ${ }^{1} *$ and Siti Jamilah Bidin ${ }^{2}$ \\ ${ }^{1}$ Department of Western Languages and Literature, Faculty of Letters, Karabuk University, Karabuk, Turkey \\ ${ }^{2}$ Department of English Language Studies, School of Languages, Civilisation and Philosophy, Universiti Utara \\ Malaysia, Sintok, Malaysia
}

\begin{tabular}{|l}
\hline ABSTRACT \\
Due to their significance in establishing a research background, citations have been under focus \\
by several researchers. However, limited studies have applied the Functional Theory in \\
analysing reporting verbs in citations. Hence, this study identifies citations in the literature \\
review chapters of $20 \mathrm{PhD}$ theses in Information Technology and Applied Linguistics by EFL \\
postgraduates within the ESL context. These PhD theses were selected purposefully. This study \\
explores qualitatively the processes based on the ideational metafunction of the Systemic \\
Functional Linguistics. The findings show that the material processes were used dominantly, \\
followed by relational, verbal, and mental processes, whereas the behavioural processes were \\
less used. The use of processes 'verbs' is influenced by field and tenor as register variables. \\
Thus, the findings imply that EFL postgraduates are unaware of using processes; therefore, they \\
should receive discipline-specific instructions. Pedagogical textbooks for academic writing \\
could be also developed based on the outputs of the present study. \\
Keywords: Academic writing; citations; EFL postgraduates; reporting verbs; Systemic \\
Functional Linguistics; transitivity system \\
First Received: $\quad$ Revised: \\
6 November 2018 \\
Final Proof Received: \\
27 May 2019
\end{tabular}

\section{INTRODUCTION}

Citation use implies familiarity with one's field and establishes the research on a credible basis of knowledge, which allows the writer to argue, claim, and justify (Thompson \& Ye, 1991; Hewings, Lillis \& Vladimirou, 2010; Petric'\& Harwood, 2013; Samraj, 2013; Swales, 2014). Positioning the writer within the academic community is also achieved by means of citations (Samraj, 2013; Petric' \& Harwood, 2013), reporting verbs and modal verbs (Thompson \& Ye, 1991; Hyland, 1999; Samraj, 2013; Yang, 2013). Thus, this high significance of using citation has attracted the interest of several studies (Swales, 1990, 2014; Hyland, 1999; Thompson, 2001, 2002; Thompson \& Tribble, 2001; Samraj, 2013; Jomaa \& Bidin, 2016, 2017; Park \& Nam, 2017).
In academic writing, integrating the citations into one's writing needs skills of advanced research and academic writing (Pecorari, 2008; Rabab'ah \& AlMarshadi, 2013) because citing involves several significant issues, such as which information to cite, who to cite, how to perform the citation and when to avoid citation (Polio \& Shi, 2012). Hence, citing information from the original sources is challenging, particularly for ESL/EFL writers of English (Law, Ting, \& Jerome, 2013; Rabab'ah \& Al-Marshadi, 2013; Rowley-Jolivet \& Carter-Thomas, 2014; Nguyen \& Pramoolsook, 2016; Jomaa \& Bidin, 2017). In this regard, little information is available about the citation practices of EFL Arab postgraduates. Therefore, the present study explores the types of processes used in citations as well as the pattern of using these processes

\footnotetext{
* Corresponding Author

Email: nayefjomaa@karabuk.edu.tr
} 
in the literature review chapters of $\mathrm{PhD}$ theses in Information Technology and Applied Linguistics.

Citations were classified by Swales (1990) into two types: integral and non-integral citations. The integral citation is characterized by giving more prominence to the cited author. On the other hand, in the non-integral citation, the name of the cited author is not integrated with the structure of the clause. Thus, the role of the cited author is less emphasised. In the integral citation, the name of the cited author, represented by a number or a pronoun, is integrated with the structure of the clause, thus functioning as a subject, an agent, a part of the noun phrase or an adjunct (Swales, 2014). In their study, Jomaa and Bidin (2016) analysed citations based on the Systemic Functional Linguistics employing two language metafunctions and could present a comprehensive taxonomy of the role of the cited author.

Choosing either type of citations is influenced by the discipline (Hyland, 1999; Thompson \& Tribble, 2001; Thompson, 2002; Okamura, 2008; Harwood, 2009; Hyland, 2009; Shi, 2012; Petric' \& Harwood, 2013; Hu \& Wang, 2014), language (Monreal \& Salom, 2011; Rowley-Jolivet \& Carter-Thomas, 2014; Hu \& Wang, 2014), writer's experience (Mansourizadeh \& Ahmad, 2011; Samraj, 2013), as well as genre (Yang, 2013; Samraj, 2013). Consequently, citation use forms a complicated procedure (Charles, 2006; Jalilifar \& Dabbi, 2012) and due to the differences of citation practices of each discipline, it is a 'danger' to adopt general rules related to citation practices because they cannot be "valid in certain contexts" (Shi, 2012, p. 145).

In Hyland's (1999) study, the integral citation was higher in the soft domain, whereas in the hard domain, the non-integral citation dominated. However, the findings of several studies related to the use of Verb controlling were inconsistent. For example, in their study, Mansourizadeh and Ahmad (2011) showed that published articles by expert writers in chemical engineering used Naming more than Verb controlling with $6.97 \%$ and $6.56 \%$, respectively, whereas unpublished papers by novice writers used Verb controlling more than Naming. The discourse-based interviews revealed that EFL students, particularly Vietnamese and Arab postgraduates, were not aware of the rhetorical functions implied in citations and they had linguistic difficulties in implicitly acquiring the conventions of citations (Nguyen \& Pramoolsook, 2016; Jomaa \& Bidin, 2017).

Studying citations was extended by several researchers, whose studies focused on denotative reporting verbs and their evaluative connotations. For instance, Yang (2013) studied reporting verbs, adopting Francis, Hunston and Manning's (1996, pp. 97-101) classification of only verb that clause, whereby the reporting verbs were classified into three groups that are parallel to the categorization in previous studies (Thompson \& Ye, 1991; Thomas \& Hawes, 1994; Hyland, 1999), including ARGUE group, THINK group, and SHOW/FIND group, as in Figure 1.

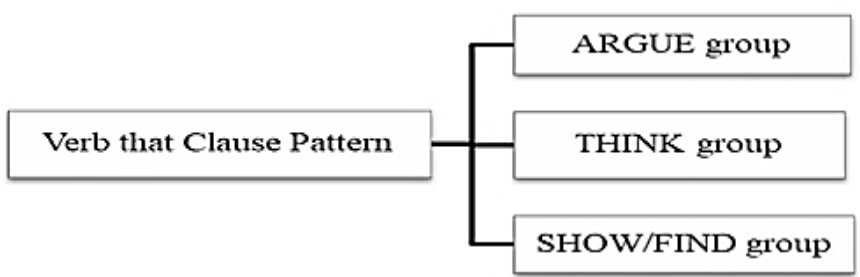

Figure 1. Verb that clause pattern (Francis, Hunston, \& Manning 1996)

In Yang's (2013) study, ARGUE group was dominant, followed by FIND/SHOW, whereas THNK group occupied the lowest percentage. However, the findings of Yang (2013) and Hyland (1999) are in contrast with those of Manan and Noor (2014). Manan and Noor (2014) showed that Malaysian masters students in an ELS program used the Research verb category with the highest percentage (44.8\%), followed by Cognition acts $(30.2 \%)$, whereas the Discourse acts had only $25.0 \%$. Genres of the soft domain, including the ELS program, should contain discourse verbs with the highest percentage, followed by research verbs, whereas cognition verbs should be less used.

An earlier study on reporting verbs by Hyland (1999) on a corpus of 80 research articles depended on a modified version of Thompson and Ye's (1991) taxonomy. Over 400 different verbs were used in citations. Disciplinary variations were clear in the density of reporting structures and forms of the verbs. Consequently, Hyland re-classified the reporting verbs into three categories according to the type of the activity: Research (real-world) Acts, Cognition Acts, and Discourse Acts. Hyland's study follows the traditional distinction between hard and soft disciplines; Discourse acts of reporting verbs were used mostly in the soft domain, whereas Research acts were used mostly in the hard one.

In this context, the first language (L1) can influence the use of citations as demonstrated by Rowley-Jolivet and Carter-Thomas (2014) who showed that expert French writers writing in English had problems related to using reporting verbs, attribution, and stance due to lack of knowledge on English reporting, and the possible effect of their mother tongue. Therefore, as Jomaa and Bidin (2016) suggested, a need arises to explore the use of these reporting verbs employing the Systemic Functional Linguistics. Another suggestion was by $\mathrm{Hu}$ and Wang (2014) stating, "Importantly, pedagogical work on linguistic resources for citation needs to be informed by a coherent functional theory of language as a semiotic tool for construing ideational, interpersonal, and textual meanings in social context" (p. 27). 
Systemic Functional Linguistics is a social theory of language use, that is structured to make simultaneously three kinds of meanings, specifically ideational, interpersonal, and textual (Halliday, 1985). Each language metafunction is associated with a register variable as demonstrated in Figure 2.
The ideational meaning, which is associated with the Field, is composed of two aspects: experiential and logical meanings. Experiential meanings express the real world by means of the processes 'verbs', as in Figure 3.

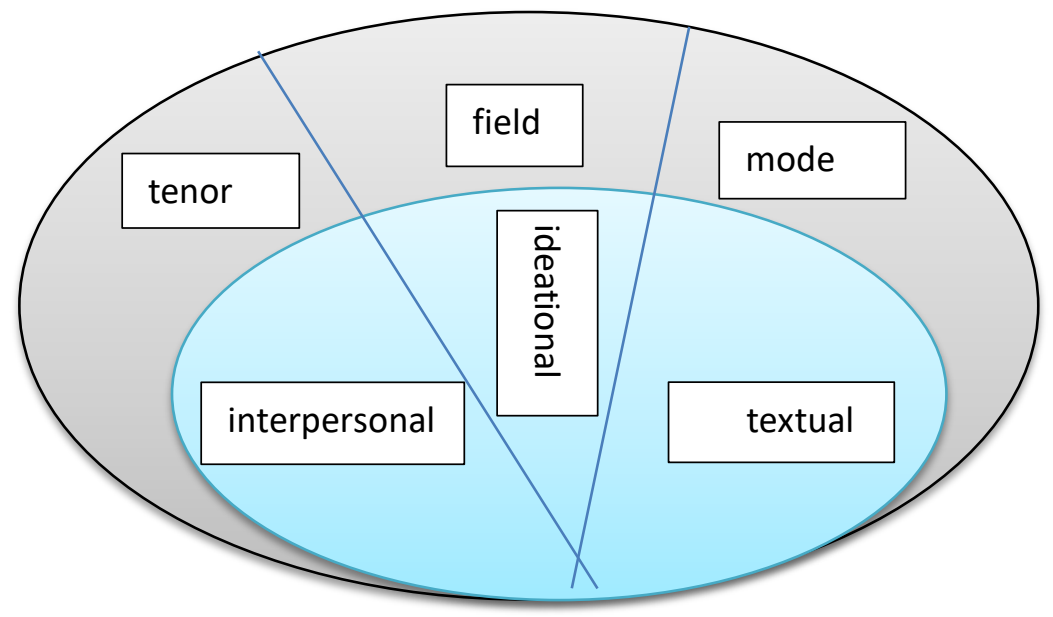

Figure 2. Metafunctional solidarity across planes (Halliday \& Martin, 1993)

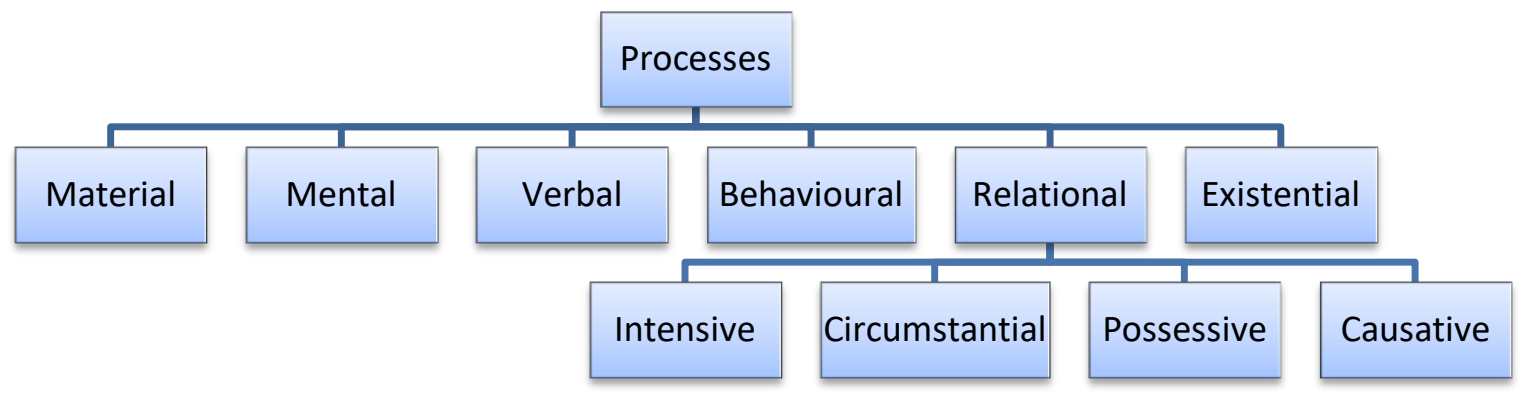

Figure 3. Processes in transitivity system (experiential meanings) (Halliday, 1985)

What distinguishes SFL from previous studies conducted on reporting verbs is the diversity of processes used in the Transitivity System, whereas in studies by Thompson and Ye (1991), Thomas and Hawes (1994), Francis et al. (1996), and Hyland (1999), only three types of verbs were involved, including textual: discourse verbs, mental: cognition verbs, and experimental: research verbs. Besides these three categories, other processes, such as behavioural, relational, and existential are also included in the Transitivity System of the SFL.

The contrasts in the findings related to citation practices and reporting verbs in previous studies and the limited studies on the performance of EFL Arab postgraduates within the ESL context (public Malaysian university) motivated the researchers in the present study to:

1) Explore the types of processes used in citations by EFL postgraduates in Information Technology and Applied Linguistics, employing the Systemic Functional Linguistics.
2) Identify the extent of variations/similarities in using the transitivity system in two different disciplines by EFL postgraduates.

\section{METHOD}

The study adopted the Systemic Functional Linguistics (Halliday, 1985) as a social theory of language, focusing mainly on analysing the processes used in citations. Swales' (1990) integral and non-integral citations were employed to identify the types of citations in the literature review chapters of Applied Linguistics and Information Technology theses. Each citation that included a single or multiple citations was considered as one citation. The ideational metafunction was adopted in analysing citations, involving the experiential meaning (Transitivity System). Each clause (simplex or complex) used in citations was analysed in order to identify the types of processes and the patterns of using each process in the literature review chapters of Applied Linguistics and Information Technology. Figure 4 describes the conceptual framework that guides the present study. 


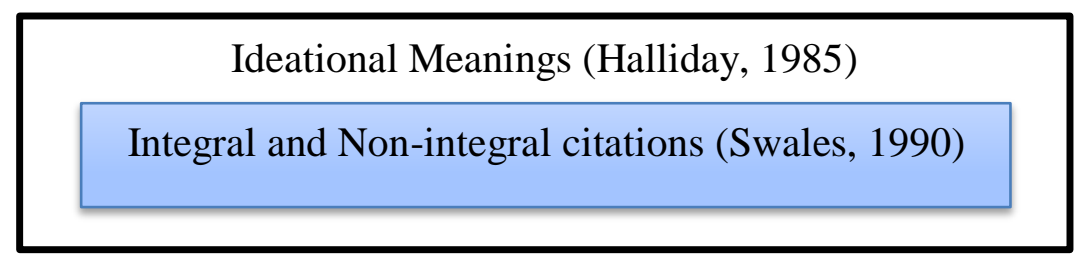

Figure 4. Conceptual framework of the present study

The present study analysed the citation types and processes qualitatively and supported the analyses by the technique of quantifying the findings. Citations that were analysed involved the integral citation, the nonintegral citation, and a mixed type of citation. In the integral citation, the name of the cited author is integrated with the clause of the citation to represent one of its constituents, as demonstrated in examples (1) and (2).

(1) According to Biber, et al. (1998), language is distinguished by structure and use. (P.2/AL/JO)

(2) Schneier (1996) posits that system security can be strengthened by several modes of operations, namely, ECB, CBC, Cipher Feedback (CFB), Output Feedback (OFB), and Counter (CTR) modes. (P.9/IT/IR)

In the non-integral citation, the name of the cited author is not integrated with the structure of the clause. Rather, it is used in parentheses. Example (3) illustrates this type of citation.
(3) People use language to express feelings and elicit meaning (Lyon, 1968, p. 424). (P.1/AL/IR)

Citations by EFL Arab postgraduates also included a mixed type of citation in which the integral and nonintegral citations were used in the same citation, as in example (4) below.

(4) In spite of the fact that her classification of the five categories seems to be overlapping and not quite distinct, Salager-Meyer's study is quite revealing in showing the different distribution of hedging categories (Crompton, 1997). (P.4/AL/YE)

In example (4), the integral citation represented by the name of the cited author 'Salager-Meyer' and the non-integral citation represented by the name of the cited author 'Crompton' are used at the same time in one citation.

Table 1.Types of citations in the literature review chapters of AL and IT

\begin{tabular}{lccc}
\hline & Integral citation & Non-integral citation & Mixed type of citation \\
\hline Applied Linguistics & $2,350(66.40 \%)$ & $1,079(30.48 \%)$ & $96(2.71 \%)$ \\
Information Technology & $1,184(54.58 \%)$ & $917(42.27 \%)$ & $60(2.76 \%)$ \\
\hline
\end{tabular}

Table 1 includes the total number of citations in the literature review chapters of $\mathrm{PhD}$ theses by EFL Arab postgraduates in two disciplines: Applied Linguistics and Information Technology. The analysis in this study is based on analysing the processes 'verbs' used in these citations excluding quotations.

\section{Participants}

The present study employed a purposeful sampling in choosing the literature review chapters of $20 \mathrm{PhD}$ theses in Applied Linguistics and Information Technology by EFL Arab postgraduates. According to Creswell (2008), it is typical in qualitative studies to study only few cases since the goal is to obtain a detailed explanation of a specific phenomenon rather than to generalise the findings. Hence, two criteria were adopted in choosing these $20 \mathrm{PhD}$ theses. First, all the authors of these PhD theses are Arab students whose native language is Arabic. Second, these PhD theses are from two different domains. These $\mathrm{PhD}$ theses were deposited in a library of one of the public Malaysian universities. Using these $\mathrm{PhD}$ theses for academic purposes was approved by the Dean of the Graduate Schools at the university. Tables 2 and 3 present details on these $20 \mathrm{PhD}$ theses.

Table 2. Descriptions of 10 Applied Linguistics literature review chapters

\begin{tabular}{|c|c|c|c|c|c|}
\hline No & Coding & Nationality & Publication Date & Number of Pages & Number of Words \\
\hline 1. & LR.1 & Iraqi & 2013 & 35 & 9,031 \\
\hline 2. & LR. 2 & Jordanian & 2014 & 75 & 20,744 \\
\hline 3. & LR.3 & Jordanian & 2014 & 87 & 21,661 \\
\hline 4. & LR.4 & Yemeni & 2014 & 62 & 12,139 \\
\hline 5. & LR.5 & Yemeni & 2014 & 35 & 8,990 \\
\hline 6 & LR.6 & Iraqi & 2014 & 69 & 18,149 \\
\hline 7. & LR. 10 & Jordanian & 2013 & 88 & 21,541 \\
\hline 8. & LR.11 & Libyan & 2014 & 89 & 22,080 \\
\hline 9. & LR.12 & Iraqi & 2013 & 117 & 31,872 \\
\hline 10. & LR.19 & Yemeni & 2015 & 79 & 19,000 \\
\hline Total & & 10 & & 736 & 185,207 \\
\hline
\end{tabular}


Table 3. Descriptions of 10 Information Technology literature review chapters

\begin{tabular}{lllccc}
\hline No & Coding & Nationality & Publication Date & Number of Pages & Number of Words \\
\hline 1 & LR.7 & Syrian & 2014 & 69 & 13,815 \\
2 & LR.8 & Iraqi & 2013 & 73 & 18,526 \\
3 & LR.9 & Iraqi & 2014 & 72 & 16,005 \\
4 & LR.13 & Jordanian & 2011 & 65 & 14,743 \\
5 & LR.14 & Jordanian & 2012 & 60 & 13,162 \\
6 & LR.15 & Palestinian & 2012 & 37 & 8,547 \\
7 & LR.16 & Yemeni & 2014 & 49 & 10,093 \\
8 & LR.17 & Jordanian & 2011 & 54 & 12,702 \\
9 & LR.18 & Iraqi & 2014 & 70 & 13,380 \\
10 & LR.20 & Jordanian & 2012 & 107 & 27,410 \\
\hline Total & \multicolumn{2}{c}{10} & 656 & 148,383 \\
\hline
\end{tabular}

Ten $\mathrm{PhD}$ theses were from Information Technology discipline (IT), whereas ten $\mathrm{PhD}$ theses were from Applied Linguistics. Table 4 presents the coding of the extracted citations from the literature review chapters of the $20 \mathrm{PhD}$ theses.

Table 4. Coding used in documenting the examples

\begin{tabular}{ccl}
\hline Thesis & Discipline & \multicolumn{1}{c}{ Nationality } \\
\hline P.1 & AL & Iraqi: IR \\
P.7 & IT & Syrian: SY \\
\hline
\end{tabular}

\section{RESULTS}

The findings address the process types of 'Transitivity System' used in the clauses of the citations and the patterns of using these processes in the literature review chapters of $20 \mathrm{PhD}$ theses. The first section presents descriptions of the process 'verbs' used in the clauses of citations to reveal the experiential meanings.

\section{Material process}

Material processes imply doing something; these reveal that some entity did something, thus involving two participants: The Actor and the Goal, as well as another optional constituent called the circumstantial. In example (1), the material processes 'conducted' and 'investigate' were used, respectively.

(1) Selim (2002) conducted an empirical study to investigate the students' acceptance of course website. (P.20/IT/JO)

These material processes were used dominantly in the literature review chapters of $\mathrm{AL}$ and IT by EFL Arab postgraduates, as in Table 5.

Table 5. Material processes in the literature review chapters of IT and AL

\begin{tabular}{ccccccccccccc}
\hline NO & Discipline & \multicolumn{1}{c}{ Participants } & \multicolumn{1}{c}{ Total } \\
\hline 1 & AL & P.1 & P.6 & P.12 & P.2 & P.3 & P.10 & P.4 & P.5 & P.19 & P.11 & $4225(55.40 \%)$ \\
& & 126 & 317 & 635 & 518 & 566 & 581 & 366 & 314 & 468 & 334 & \\
2 & IT & P.8 & P.9 & P.18 & P.13 & P.14 & P.17 & P.20 & P.16 & P.7 & P.15 & $3398(44.60 \%)$ \\
& & 821 & 197 & 226 & 359 & 242 & 216 & 649 & 316 & 191 & 181 & \\
\hline
\end{tabular}

Although Applied Linguistics and Information Technology belong to two different fields, material processes dominated the literature review of both; this implies that the discipline as a field has an effect on student's high use of material processes in IT. On the other hand, other factors such as students' educational background, insufficient knowledge on using processes or other unknown reasons could probably be the motivation for students' high use of material processes in the literature review of AL. EFL Arab students in both $\mathrm{AL}$ and IT PhD theses also followed a similar pattern of using the material processes; they used a high number of material processes in the sections related to the background of the study, theories, definitions, and concepts. Then, this was followed by a higher number of material processes in the sections related to previous related studies. Finally, the number of material processes decreased in the section related to the theoretical/conceptual framework. Figures (5) and (6) demonstrate the pattern of using the material processes in the literature review of AL and IT theses.

\section{Mental process}

Mental processes are used in clauses of citations to express realizations of thinking, feelings, and perceiving. Thus, these mental processes are classified into three subcategories: (A) Cognition, (B) Affection, and (C) Perception. These processes are used in a clause simplex as well as a clause complex, such as 'consider', 'believes', and 'feels' in the examples (2), (3), and (4), respectively.

(2) For example, in [22] the authors consider NoA only in the current time interval.(P.15/IT/PA)

(3) Shapiro (1981), on the other hand, believes that 'the study of PD should be in terms of general concepts such as power, conflict, control, or domination' '(p.243) (P.12/AL/IR)

(4) Mehlinger $(1995, p .3)$ feels that there is no need to be careful and thoughtful in editing the materials". (P.6/AL/IR)

Based on the findings, Table 6 shows the number and percentage of the mental processes in the literature review chapters of Applied Linguistics and Information Technology. 


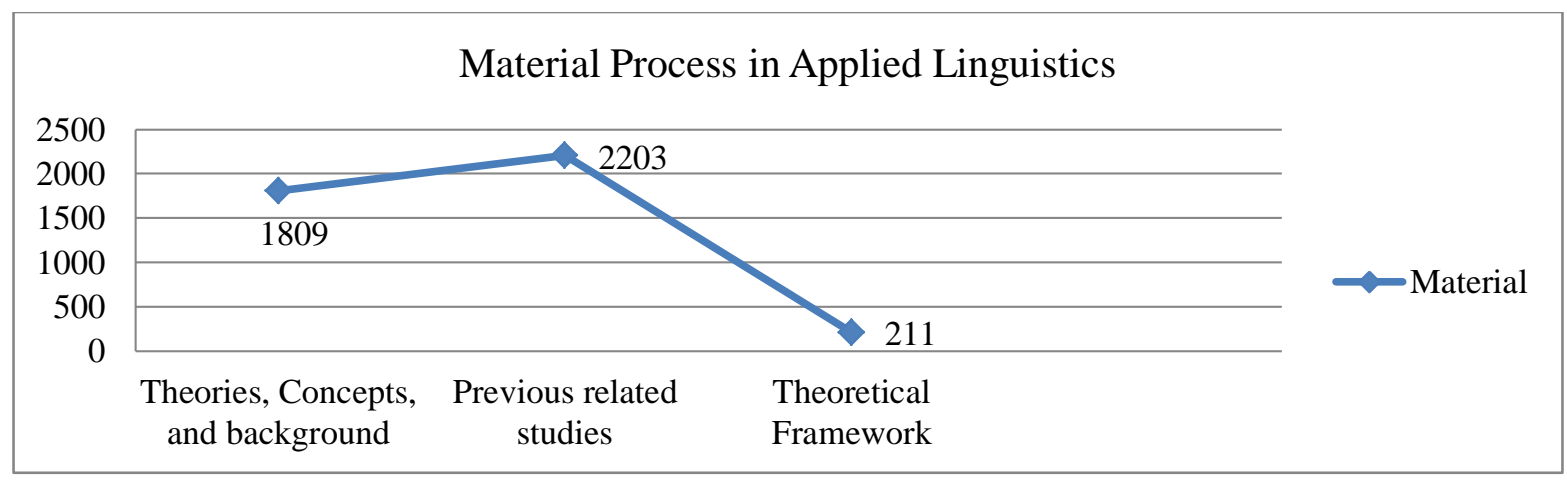

Figure 5. Pattern of using material processes in the literature review chapters of AL

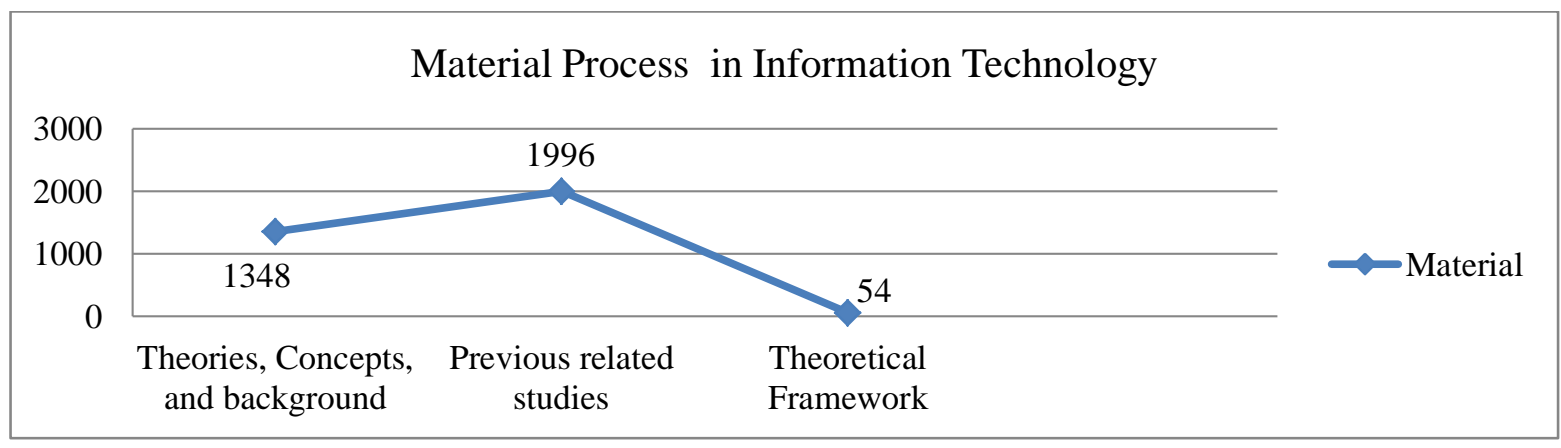

Figure 6. Pattern of using material processes in the literature review chapters of IT

Table 6. Mental processes in the literature review chapters of AL and IT theses

\begin{tabular}{ccrrrrrrrrrrr}
\hline NO & Discipline & \multicolumn{1}{c}{ Participants } & \multicolumn{1}{c}{ Total } \\
\hline 1 & AL & P.1 & P.6 & P.12 & P.2 & P.3 & P.10 & P.4 & P.5 & P.19 & P.11 & 975 \\
& & 43 & 56 & 200 & 134 & 94 & 91 & 67 & 109 & 96 & 85 & $(70.80 \%)$ \\
2 & IT & P.8 & P.9 & P.18 & P.13 & P.14 & P.17 & P.20 & P.16 & P.7 & P.15 & 402 \\
& & 45 & 12 & 26 & 54 & 34 & 54 & 91 & 43 & 12 & 31 & $(29.20 \%)$ \\
\hline
\end{tabular}

Though mental processes were used differently in terms of number and patterns, they occupied the fourth rank in the literature review chapters of AL and IT. The use of mental processes in $\mathrm{AL}$ as a soft domain with a high percentage compared to IT reflects the effect of domain to which each discipline belongs. In other words, this performance highlights the effect of field as a probable variable that influences students' use of processes in citations. Figure 7 demonstrates how mental processes were used with a high percentage in sections related to theories, background, and definitions, then they decreased in the sections related to previous related studies, and finally they decreased sharply to 58 mental processes in the section related to the theoretical/conceptual framework.

On the other hand, in IT, 178 mental processes were used in sections related to theories, background and definitions. Then, they increased to 205 mental processes in the related studies section, followed by a decrease to reach 19 mental processes in the section of the theoretical/conceptual framework, as illustrated in Figure 8 .

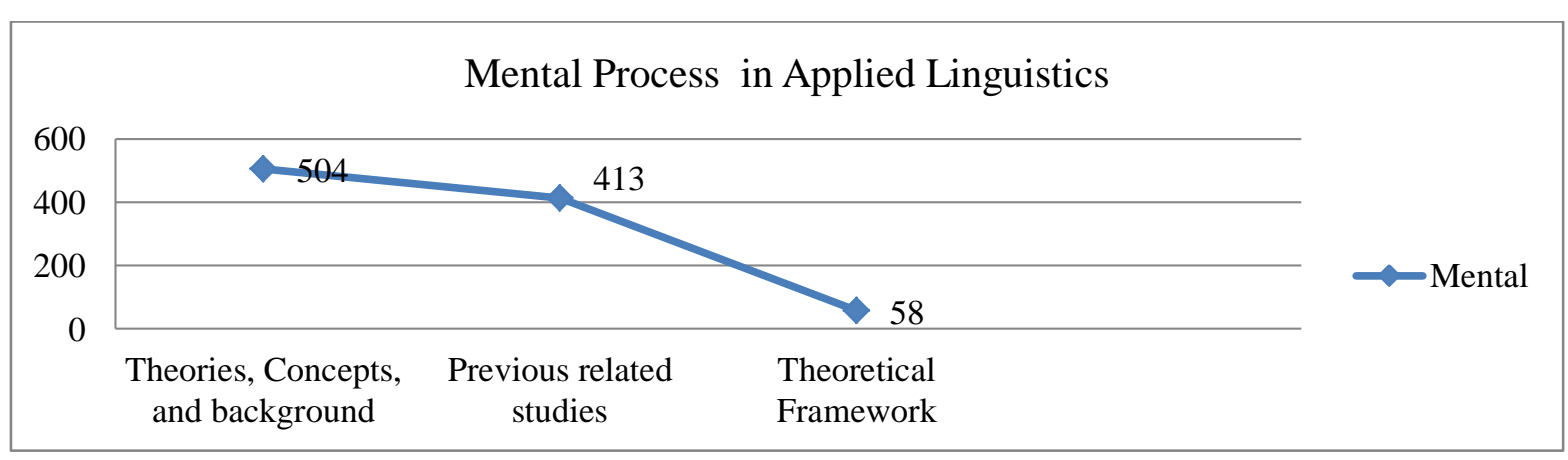

Figure 7. Pattern of using mental processes in the literature review chapters of AL 


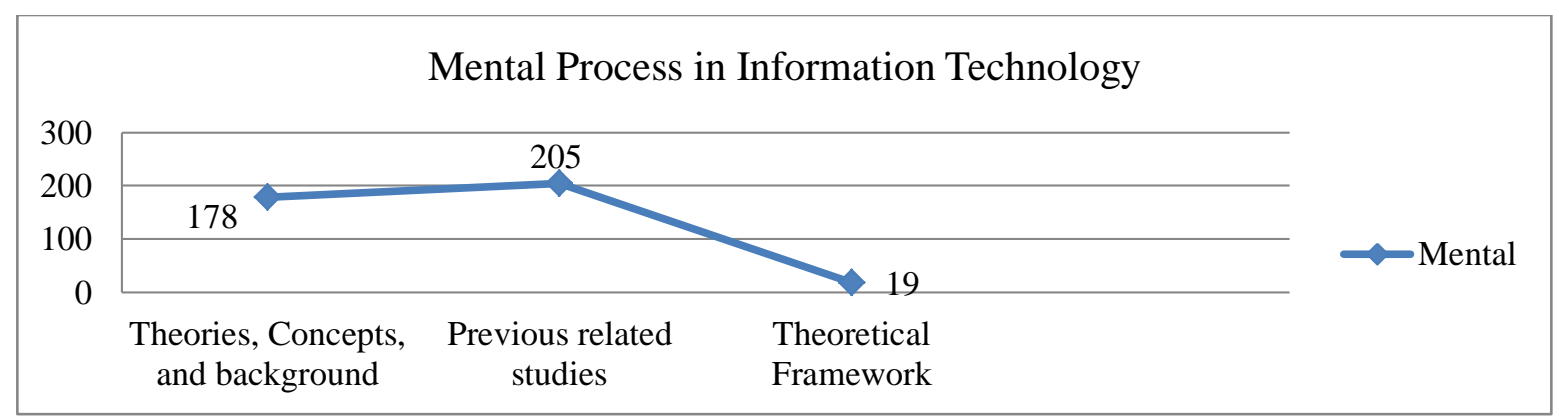

Figure 8. Pattern of using mental processes in the literature review chapters of IT theses

\section{Verbal process}

Verbal processes imply saying and arguing which occupied the third rank in terms of frequencies. Examples (5), (6), and (7) demonstrate using 'conclude', 'indicates', and 'mentions' as verbal processes in citations, respectively.

(5) Xia and King (2002) conclude that alignment has been reported as an organisation wide issue that directly influences the company's overall performance. (P.17/IT/JO)
(6) Tennen (1983) indicates that overlap is unintentional in which it occurs naturally in simultaneous speech. (P.12/AL/IR)

(7) He mentions that these two religious rituals are practiced in the two cultures differently. (P.11/AL/LI)

In Table 7, there is a demonstration of the number and percentage of using the verbal process in the literature review chapters of Applied Linguistics and Information Technology.

Table 7. Verbal processes in the literature review chapters of AL and IT

\begin{tabular}{rcrrrrrrrrrll}
\hline NO & Discipline & \multicolumn{1}{c}{ Participants } & \multicolumn{1}{c}{ Total } \\
\hline 1 & AL & P1 & P6 & P12 & P.2 & P3 & P10 & P4 & P5 & P19 & P11 & 2086 \\
& & 97 & 149 & 289 & 231 & 249 & 439 & 132 & 70 & 193 & 237 & $(72.40 \%)$ \\
2 & IT & P8 & P9 & P18 & P13 & P14 & P17 & P20 & P16 & P7 & P15 & 796 \\
& & 129 & 36 & 50 & 71 & 76 & 108 & 194 & 30 & 64 & 38 & $(27.60 \%)$ \\
\hline
\end{tabular}

Similar to mental processes, using verbal processes in AL and IT was influenced by discipline; AL is a soft domain that is based on arguments, thus it included a high frequency of verbal processes, whereas IT is a hard domain that had a lower number of verbal process frequencies. In spite of the differences in the number and percentage of the verbal processes, AL and IT shared a similar pattern represented by a somehow high usage in the sections related to theories, definitions and background, followed by an increasing number in the sections of the previous related studies. Then, the verbal processes decreased in the section related to the theoretical/conceptual framework, as demonstrated in Figures (9) and (10).

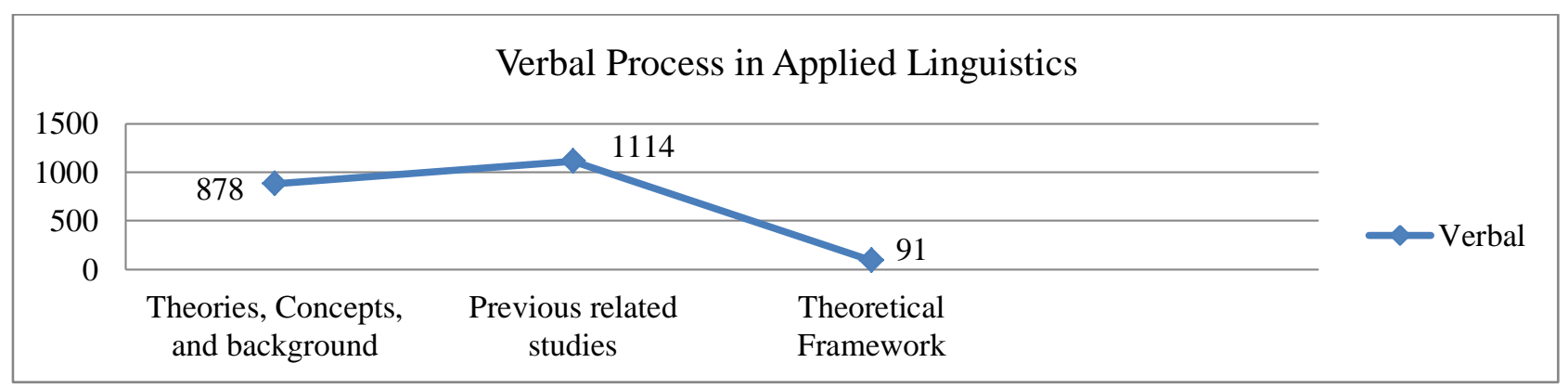

Figure 9. Patterns of using verbal processes in the literature review chapters of AL

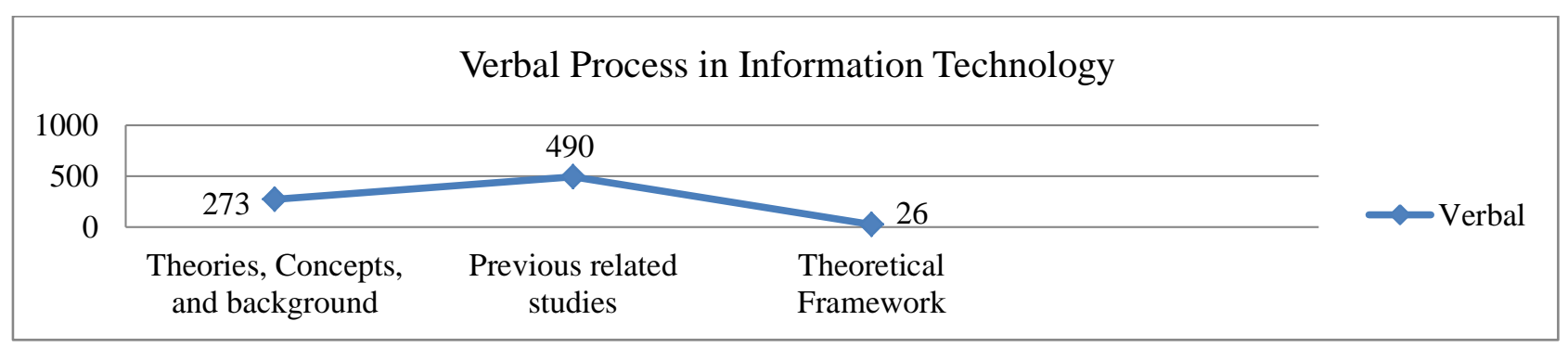

Figure 10. Patterns of using verbal processes in the literature review chapters of IT 


\section{Behavioural process}

Behavioural Processes are physiological and psychological behaviours which intermediate between material and mental processes, such as 'noticed' and 'observed' in examples (8) and (9), respectively.

(8) In examining the discourse of higher education, Fairclough (1993) noticed interdiscursivity or mix not only on the discourse level, but also on the genre and style levels (P.2/AL/JO)
(9) In another study, James (1984) observed the impact of difficulties on a more comprehensive communicative success. (P.3/AL/JO)

Table 8 shows the use of behavioural processes, including number and percentage in the literature review chapters of Applied Linguistics and Information Technology.

Table 8. Behavioural processes in the literature review chapters of AL

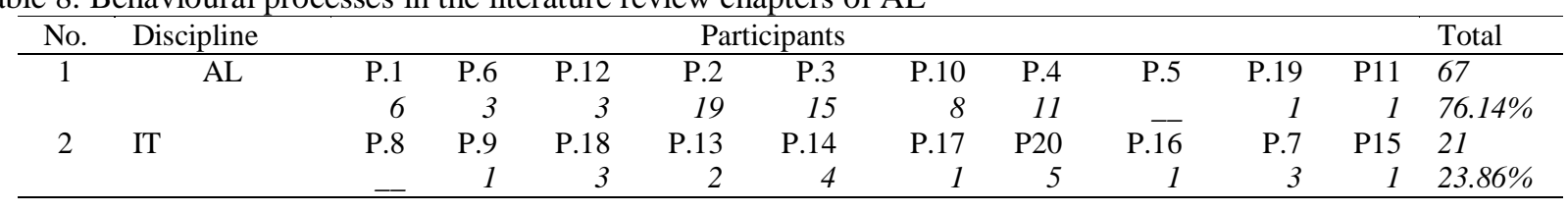

The literature review chapters of Applied Linguistics and Information Technology shared similar characteristics represented by a low number of behavioural processes due to the tendency of EFL Arab students to use processes denoting material activities, statements or beliefs rather than behavioural ones. Only 67 behavioural processes were used in the literature review chapters of $\mathrm{AL}$, whereas 20 processes were employed in the literature review chapters of IT.

\section{Relational process}

Relational processes refer to being processes which imply that something is. These relational processes are of two subtypes: (A) Attributive and (B) Identifying.

\section{Intensive process}

In Relational Attributive Intensive processes, a relationship is established between two terms using either the process ' $b e$ ' or one of its synonyms, as in examples (10) and (11).

(10) It is Chomsky's (1965, p.3) idealized way in approaching language that aims to specify the universal principles which characterize the innate structure of language . (P.1/AL/IR)

(11) Halliday's (1985) approach is functional grammar as opposed to 'formal grammar' and functional as it intends to interpret the text, the system and the linguistic structures. (P.2/AL/JO)

Relational intensive processes can be in the passive form when used as Identifying Intensive processes. Hence, the Identifying Intensive processes contrast with the Attributive Intensive processes semantically and grammatically. The semantic difference implies that the clause with an identifying intensive process is to define, whereas the clause with an Attributive Intensive process is to classify or describe. Examples (12) and (13) clarify how the Identifying Intensive processes 'is' and 'are' were used.

(12) Elbow (1973) is one of the most famous researchers who follow this method. (P3/AL/JO)

(13) Dewey (1933) and Schon (1983, 1987) are two of the most cited contributors to foundational concepts of reflective practice (York-Barr et al., 2006). (P.5/AL/YE)

Table 9. Relational intensive processes in the literature review chapters of AL

\begin{tabular}{|c|c|c|c|c|c|c|c|c|c|c|c|c|}
\hline No. & Discipline & \multicolumn{9}{|c|}{ Participants } & \multicolumn{2}{|r|}{ Total } \\
\hline 1 & $\mathrm{AL}$ & P.1 & P.6 & P.12 & P. 2 & P. 3 & P.10 & P.4 & P.5 & P.19 & P11 & 1557 \\
\hline & & 91 & 71 & 296 & 227 & 138 & 200 & 121 & 83 & 125 & 205 & $65.30 \%$ \\
\hline 2 & IT & P. 8 & P. 9 & P. 18 & $\mathrm{P} 13$ & P.14 & P.17 & P. 20 & $\mathrm{P} 16$ & P. 7 & P15 & 827 \\
\hline & & 75 & 86 & 74 & 95 & 80 & 73 & 150 & 86 & 54 & 54 & $34.70 \%$ \\
\hline
\end{tabular}

Relational Intensive processes occupied the second rank in terms of frequencies in the literature review chapters of Information Technology, whereas in AL Relational Intensive processes had the third rank following the verbal processes. In addition, the two fields, AL and IT, were also different in the patterns of using the Relational Intensive processes; AL started with a high number in sections related to theories, concepts and background, then the number of the Relational Intensive processes decreased in the related studies sections till it reached 77 processes. On the other hand, Relational Intensive processes in IT started with 392 processes in the theories, concepts and background sections, then the number increased in the sections related to the previous studies, till it reached 19 processes. Disciplinary variations were evident due to the disciplinary influences represented by field, as illustrated by Figures (11) and (12).

The high percentage of the Relational Intensive processes is one of the most notable characteristics in the literature review chapters of IT following the material processes since students in the hard domain use processes to reveal facts rather than argue about them, whereas students in the soft domains tend to use verbal processes in order to 'argue, state, claim'. These differences clarify the disciplinary influence of field as a register variable on using processes in citations. 


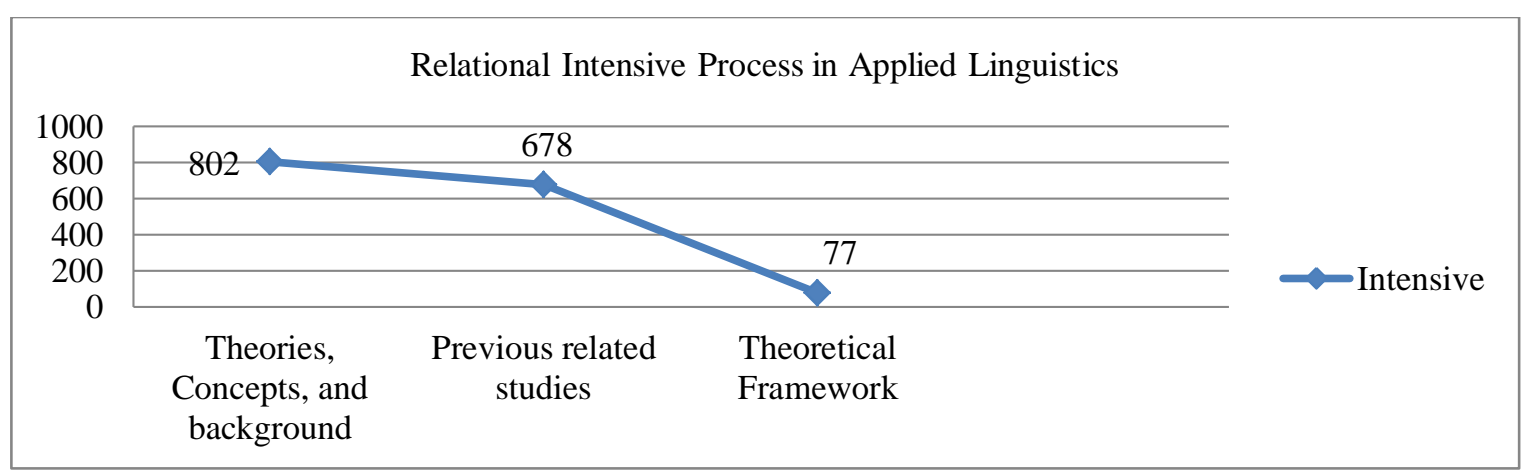

Figure 11. Patterns of using intensive processes in the literature review chapters of AL

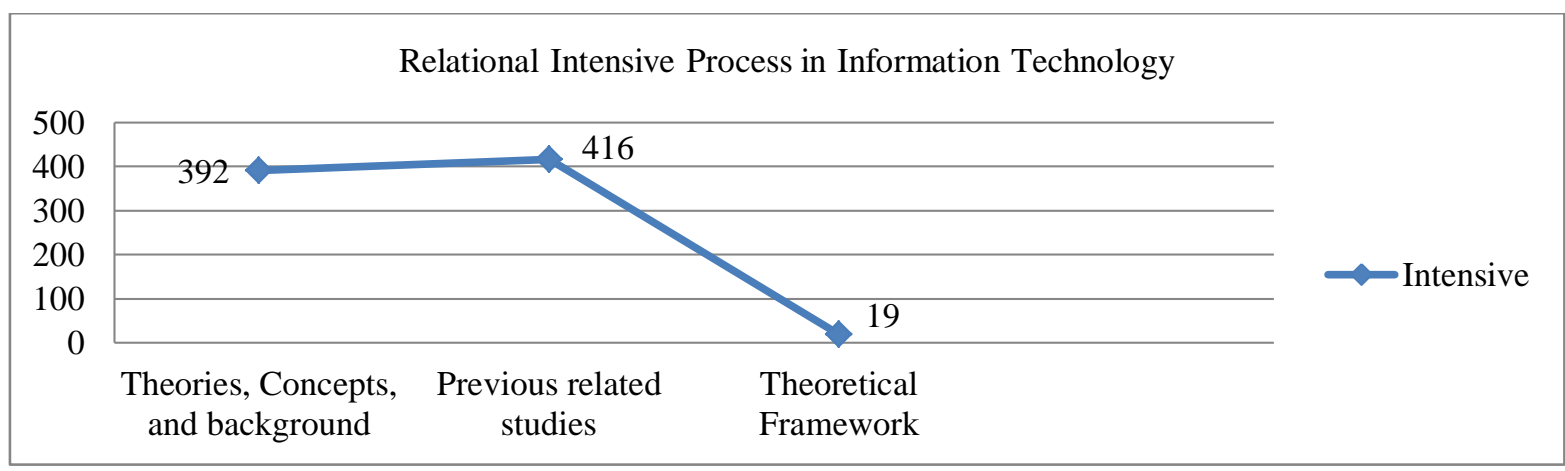

Figure 12. Patterns of using intensive processes in the literature review chapters of IT

\section{Relational: circumstantial process}

These types of processes imply meaning about the circumstantial dimension, such as location, time, manner, and cause, like the process 'date back' in example (14).

(14) This means that women are a subordinate minority group. Research on men's and women's language use date back to the mid 1970s but these were conducted largely in the English-speaking countries (Holmes, 2009). (P.4/AL/YE)

Though the Circumstantial processes were higher in the literature review chapters of AL compared to IT, they were the least type of processes used by EFL Arab postgraduates due to utilising prepositional constituents as a circumstantial to refer to time or place rather than using circumstantial processes as in Table 10.

Table 10. Circumstantial processes in the literature review chapters of AL and IT

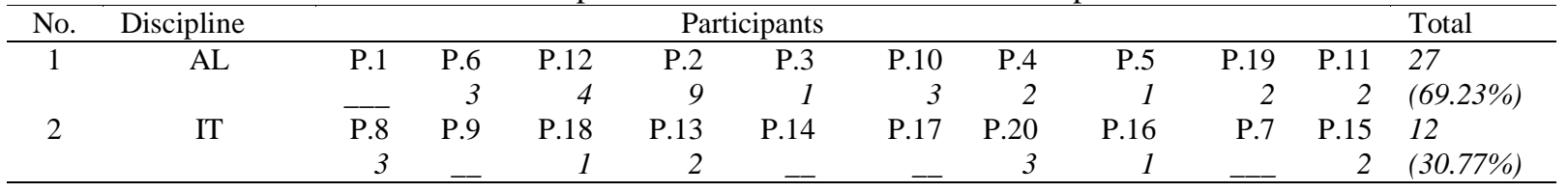

\section{Relational: Possessive process}

Possessive processes imply meanings about ownership and possessions between participants of the clause, such as to have, had, belong, and have got, as in example (15).
(15) Al-Samawi's study, however, (1995) has some weaknesses. (P.19/AL/YE)

Table 11 shows the number and percentage of using the Relational Possessive processes.

Table 11. Relational possessive processes in the literature review chapters of AL and IT

\begin{tabular}{ccrrrrrrrrrrr}
\hline No. & Discipline & \multicolumn{10}{c}{ Participants } & \multicolumn{1}{c}{ Total } \\
\hline 1 & AL & P.1 & P.6 & P.12 & P.2 & P.3 & P.10 & P.4 & P.5 & P.19 & P.11 & 517 \\
& & 10 & 32 & 135 & 59 & 81 & 42 & 30 & 21 & 49 & 58 & $66.37 \%$ \\
2 & IT & P.8 & P.9 & P.18 & P.13 & P.14 & P.17 & P.20 & P.16 & P.7 & P.15 & 262 \\
& & 38 & 19 & 25 & 37 & 31 & 24 & 51 & 18 & 12 & 7 & $33.63 \%$ \\
\hline
\end{tabular}

Using the Relational Possessive processes in $\mathrm{AL}$ and IT theses was varied; the number of possessive processes in $\mathrm{AL}$ was higher. This finding might be attributed to the disciplinary influences and the high density of citations in AL. The two fields represented by AL and IT are also different in terms of using the 
patterns of possessive processes. In AL literature review chapters, a high number of possessive processes was used in the theory and background sections, then it decreased moderately in the related studies sections, and the theoretical/conceptual framework. On the other hand, in the literature review chapters of IT, the highest number of relational possessive processes was in the related studies sections. Figures 13 and 14 represent a demonstration of the Relational possessive pattern used in the literature review chapters of Applied Linguistics and Information Technology $\mathrm{PhD}$ theses.

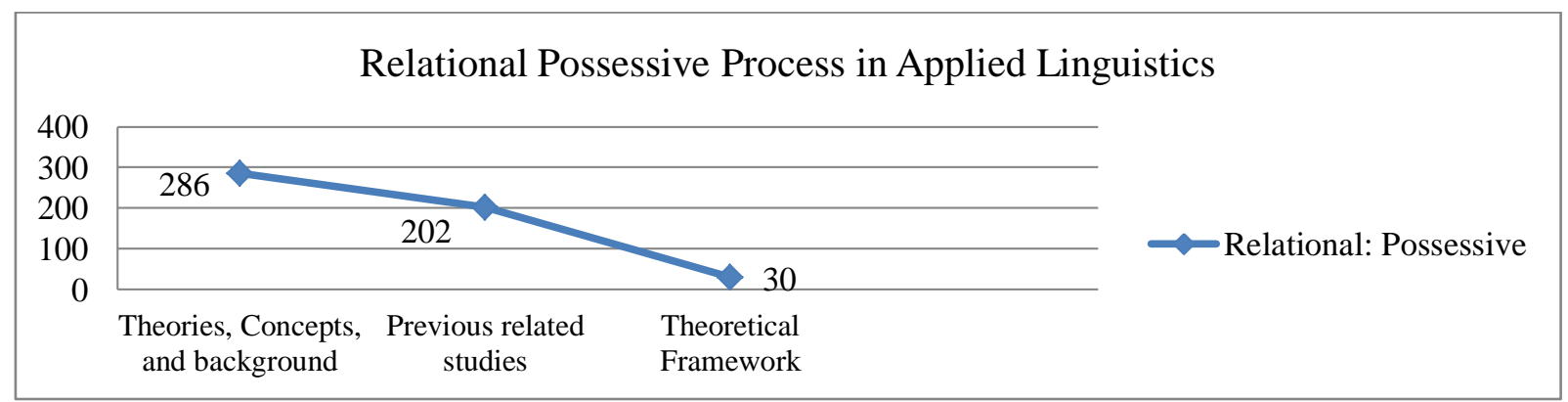

Figure13. Pattern of using possessive processes in the literature review chapters of AL

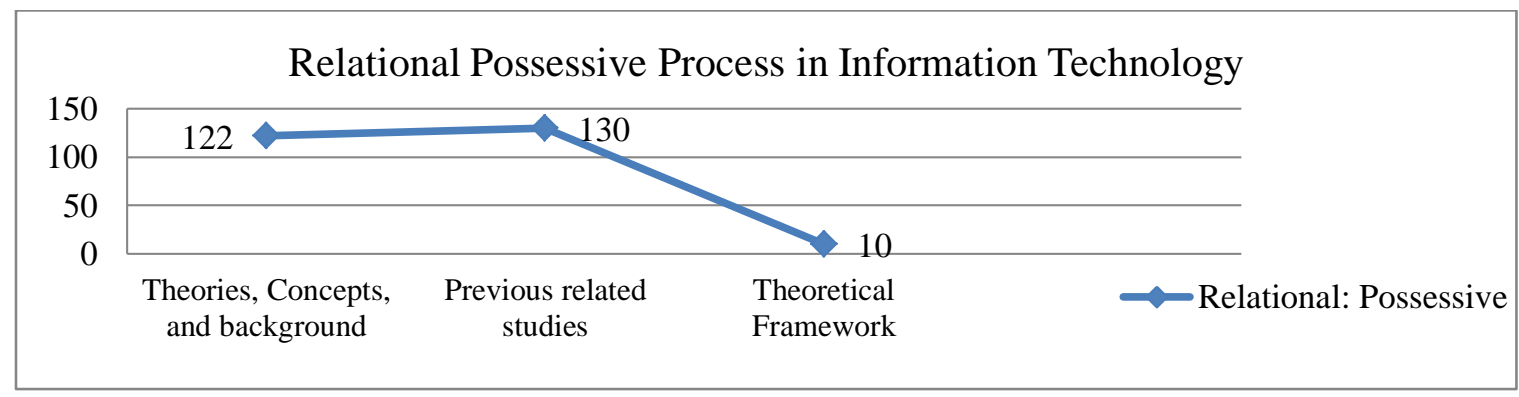

Figure14. Pattern of using possessive processes in the literature review chapters of IT

\section{Relational: Causative process}

Causative processes were another subtype of relational processes used in the literature review chapters of $\mathrm{AL}$ and IT by EFL Arab postgraduates. These causative processes involve a nominal constituent that functions as an 'Agent'. Clauses with causative processes involve another clause with either an explicit or an ellipsed process, particularly with Attributive Intensive processes. In such case, the 'Agent' has another function called an 'Attributor'. Examples (16), (17), (18), and (19) are citations with clauses that include causative processes.

(16) This general reversal of thought from the Western gender pattern made Ibrahim (1986, p. 116) to conclude: Unlike women in the rest of the world, Arabic- speaking females tend to approximate Standard Arabic to a lesser degree than Arabicspeaking males. (P.1/AL/IR)

(17) Eckert (1989) assumed that the fact that women appear to be universally granted less power than men will certainly not cause all women and men to act alike, given all the other factors that are involved. (P.1/AL/IR)
(18) However, they had not made it clear as to how far does the slower congestion window growth may adversely effect short connections... (P.7/IT/SY)

(19) This causes Littlewood (1992) to affirm that language and communication are very closely related but they are not the same phenomenon. (P.19/AL/YE)

In example (16), the citation includes several clauses; the first clause has the causative process 'made', whereas the second clause involves the process 'conclude'. The nominal group 'This general reversal of thought from the Western gender pattern' functions as an 'Agent' participant, whereas the cited author 'Ibrahim' is a nominal constituent that functions as the 'Sayer'. In example (18), one of the clauses involves the causative process 'made'. The 'Agent: Attributor' constituent is realized by the pronoun 'they'. This clause is followed by another clause with an ellipsed process. Table 12 demonstrates the number of the causative processes used in the 20 literature review chapters of $\mathrm{AL}$ and IT.

Table 12. Causative processes in the literature review chapters of AL and IT

\begin{tabular}{|c|c|c|c|c|c|c|c|c|c|c|c|}
\hline \multicolumn{4}{|c|}{ Discipline } & \multicolumn{7}{|c|}{ Frequency of the process for each thesis } & \multirow{2}{*}{$\begin{array}{c}\text { Total } \\
120\end{array}$} \\
\hline $\mathrm{AL}$ & P.1 & P.6 & P.12 & P.2 & P.3 & P.10 & P.4 & P.5 & P.19 & P.11 & \\
\hline $\mathrm{F}$ & 4 & 22 & 10 & 21 & 8 & 14 & 4 & 23 & 10 & 4 & $71.85 \%$ \\
\hline IT & P.8 & P.9 & P.18 & P.13 & P.14 & P.17 & P. 20 & P.16 & P.7 & P. 15 & 47 \\
\hline $\mathrm{F}$ & 5 & $=$ & 1 & 15 & 4 & 7 & 7 & 6 & & 2 & $28.15 \%$ \\
\hline
\end{tabular}


The literature review chapters of AL have a higher number of causative processes compared with IT. In general, causative processes were less used in the literature review chapters of AL and IT. This may reveal that writers of these $\mathrm{PhD}$ theses are affected by the sources from which they cite the information, and such sources involve only few examples of the causative processes. The tendency of EFL Arab postgraduates to use processes that are most common which refer to statements, suggestions, research analysis and procedures that attract the attention of the readers to something significant or really happened is another possible reason. In summary, the relational processes involved two types of processes. Clauses with attributive processes are not reversible; the passive cannot be made. On the other hand, clauses with identifying processes are reversible; passive can be made. Relational processes also included circumstantial, possessive and causative processes. The differences in frequencies and percentage between $\mathrm{AL}$ and IT show that field is a register variable that affects the use of the Transitivity System in clauses of citations.

\section{Existential Process}

Existential types of processes represent the existence of something or that something happened. In clauses that include existential processes, 'there' must be used, which does not have representational functions; 'there' is used because the clause needs a subject. Examples of Existential processes are 'be, exist, arise', as in (20), (21), and (22).

(20) According to al-'Ubayd (2002), there are three different methods for translating the Holy Quran: literal, lexical and interpretive translation. (P.11/AL/LI)

(21) Thus, sociolinguistics argue that language exists in social context and it is "a very social phenomenon" (Trudgill, 2000, p.21). (P.1/AL/IR)

(22) There has been a great emphasis on the importance of teaching and instructional performance of college teachers (Wlodarsky \& Walters, 2006) and on the improvement of higher education teaching quality (Levine, 2005) .(P.5/AL/YE)

Based on the findings, Table 13 clarifies the number and percentage of using Existential processes in the literature review chapters of Applied Linguistics and Information Technology.

Table 13. Existential processes in the literature review chapters of AL and IT

\begin{tabular}{|c|c|c|c|c|c|c|c|c|c|c|c|c|}
\hline No. & Discipline & & & & Partici & & & & & & & Total \\
\hline 1 & $\mathrm{AL}$ & P.1 & P.6 & P.12 & P. 2 & P.3 & P.10 & P.4 & P.5 & P.19 & P.11 & 97 \\
\hline & & 8 & 7 & 21 & 5 & 9 & 14 & 8 & 7 & 4 & 14 & $58.80 \%$ \\
\hline 2 & IT & P. 8 & P.9 & P.18 & P.13 & P.14 & P.17 & P.20 & P.16 & P.7 & P.15 & 68 \\
\hline & & 2 & 1 & 10 & 6 & 8 & 10 & 8 & 10 & 6 & 7 & $41.20 \%$ \\
\hline
\end{tabular}

Existential processes were also among the least type of processes in the literature review chapters of $\mathrm{AL}$ and IT.

Based on the abovementioned discussions related to types of processes in the literature review chapters of Applied Linguistics and Information Technology, Figure 15 summarises the frequencies for each type of processes in the clause of citations.

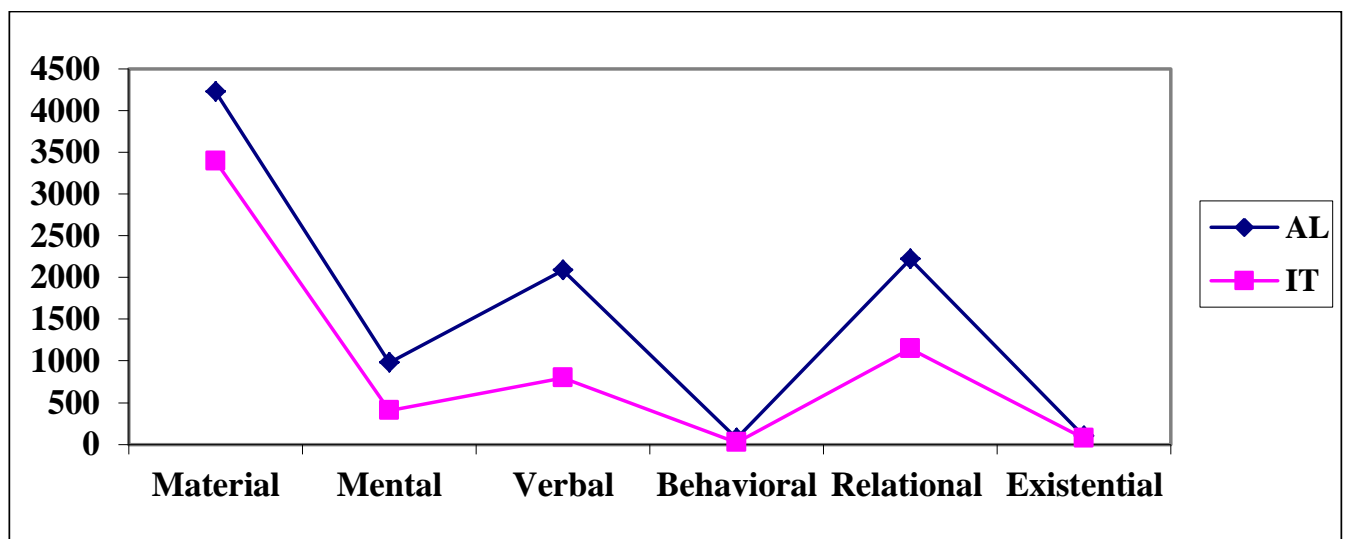

Figure 15. Frequencies of process 'Transitivity System' in the literature review chapters of AL and IT

In brief, six types of processes were found in the citations of the literature review chapters of AL and IT $\mathrm{PhD}$ theses. The main issue in using these processes is the dominance of material processes in the literature review chapters of the two groups of $\mathrm{PhD}$ theses in spite of their different domains of knowledge. Using the material process dominantly in the hard domain seems reasonable and appropriate since this process reveals real-world and tangible actions. On the other hand, the overuse of the material process in AL contrasts with the conventions of using processes in the soft domain. This may highlight EFL Arab postgraduates' unawareness of the implied evaluation of these types of processes. Another noticeable aspect is the dominance of relational 
processes, particularly intensive processes in IT following the material processes. It seems that the intensive processes add a kind of authenticity to studies in the hard domains because they reveal real and/or true aspects.

\section{DISCUSSION}

The present study is based on identifying the citation types and exploring the process 'verbs' in the literature review chapters of $20 \mathrm{PhD}$ theses in Applied Linguistics and Information Technology by EFL Arab postgraduates at one of the public Malaysian universities. Swales' (1990) classification of the citation types was adopted in identifying the citations types, and the Ideational Metafunction of the SFL (Halliday, 1985) was the basis for analysing the types of processes in each clause of the citation.

The influence of field as a register variable was evident in the use of the Transitivity System. In spite of their different fields, Applied Linguistics was similar to Information Technology in the high density of the material processes as in Jalilifar, White, \& Malekizadeh (2017), whereas the behavioural and existential processes had the smallest number and percentage. Insufficient knowledge on using citations, the possible effect of the mother tongue, and unawareness of using the Transitivity System in the different disciplines can be a reason for EFL Arab postgraduates' process performance. The realized variations in the employment of certain features, such as nominal groups in textbooks of hard and soft sciences, can be pedagogically inspiring (Jalilifar, White, \& Malekizadeh, 2017). Therefore, Hyland (2006) argues that disciplines have shared features as a register of academic discourses. This argument could justify the similarities of the use of the transitivity system in citations of the literature review chapters of AL and IT despite their different disciplines.

The register variable, field discussed in the present study, proved to be an effective element in using citations; therefore, it cannot be neglected when conducting further future studies on citations. In this regard, Hyland (2017) suggested that students have to learn writing in community-specific ways. Regarding the discipline of Information Technology, the disciplinary influence affected the use of the processes through the highest number of material processes, followed by verbal and mental ones, as in other studies (Hyland, 1999; Thomas \& Hawes, 1994). This finding is supported by another study (Jomaa \& Bidin, 2019) which showed the dominant use of Expansion due to employing non-projecting processes represented by material processes in the first clause of the clause complex citation. However, the relational processes which occupied the second rank in terms of number and percentage in the present study were not included in previous studies which depended mostly on taxonomies of three classifications only: experimental research verbs, textual discourse verbs, and mental cognition verbs (Francis et al., 1996; Hyland, 1999; Thomas \&
Hawes, 1994; Thompson \& Ye, 1991). The use of the relational processes in IT with a high percentage following the material ones in the present study implies that the taxonomies of reporting verbs adopted in previous studies were not sufficient in presenting a comprehensive description of the use of reporting verbs in the citation practices. Consequently, applying the Functional Theory in analysing citations as suggested by $\mathrm{Hu}$ and Wang (2014) and Jomaa and Bidin (2016) resulted in significant and comprehensive findings with more diversities of the processes used in the clauses of the citations that go beyond the three categories of reporting verbs adopted in previous studies (Francis et al., 1996; Hyland, 1999; Thomas \& Hawes, 1994; Thompson \& Ye, 1991).

Hence, studying other genres by native speakers, ESL, and EFL writers through employing the Functional Theory can add more explanations to the use of the processes in citations. However, the present study was limited to only identifying citations. Therefore, the citations with clause complexes can be analysed further based on the functional theory in order to explore the logico-semantic relationships between clauses of a clause complex. In addition, more studies are required to explore the challenges faced by EFL writers in citations in writing the different genres. The gender differences in the use of the processes by Emilia, Moecharam, and Syifa (2017) could imply that exploring the processes in citations of males and females' writings would be interesting.

\section{CONCLUSIONS}

The present study aimed at exploring the use of process 'verbs' in the citations of EFL Arab postgraduates when writing the literature review chapters of their $\mathrm{PhD}$ theses, as well as identifying the extent of variations and similarities in utilising these processes. Although the present study is limited to $20 \mathrm{PhD}$ theses, the use of the Functional Theory (Halliday, 1985; Halliday \& Martin, 1993; Halliday \& Matthiessen, 2014) resulted in identifying all types of processes employed in citations. These involved material, verbal, mental, relational, behavioural, and existential processes. The dominant use of material processes in two different disciplines (Applied Linguistics and Information Technology) that belong to two contrasting domains probably demonstrates firstly unawareness of EFL Arab postgraduates of the implied evaluation of using processes in citations. Secondly, the writer's native language should be considered when conducting future genre analyses on citations and process 'verbs' due to the possible influence of L1 on L2 academic writing. Thirdly, as Hyland (2006) argues, disciplines have shared features as a register of academic discourses. Consequently, a necessity arises to adopt a disciplinespecific approach in EAP teaching and learning. It is therefore pedagogically significant to enhance the awareness of novice writers towards citation practices in different academic genres. One approach to academic 
language is influenced by a genre-based literacy programme (Christie, 1992, 1999) that is grounded in SFL (Halliday, 1985; Halliday \& Martin, 1993; Halliday \& Matthiessen, 2014). Therefore, explicitly teaching academic registers is supported by a genrebased pedagogy to cope with the students' writing needs. The outputs of such studies can be employed pedagogically to equip students in higher education institutions with more knowledge and instructions on citations and academic writing.

\section{ACKNOWLEDGEMENTS}

We would like to thank the 20 EFL Arab doctors whose $\mathrm{PhD}$ theses were analysed. We also would like to thank University Utara Malaysia for making this study possible.

\section{REFERENCES}

Charles, M. (2006). Phraseological patterns in reporting clauses used in citation: A corpus-based study of theses in two disciplines. English for Specific Purposes, 25(3), 310-331. doi: 10.1016/j.esp.2005.05.003

Christie, F. (1992). Literacy in Australia. ARAL, 12, 142-155. doi: 10.1017/S0267190500002191

Christie, F. (1999). Genre theory and ESL teaching: A systemic functional perspective. TESOL Quarterly. 33(4), 759-764. doi: 10.2307/3587889

Creswell, J.W. (2008). Educational research: Planning, conducting and evaluating quantitative and qualitative research. (3rd ed.). USA, Boston: Pearson Education.

Emilia, E., Moecharam, N. Y., \& Syifa, I. L. (2017). Gender in EFL classroom: Transitivity analysis in English textbook for Indonesian students. Indonesian Journal of Applied Linguistics, 7(1), 206-214. doi: 10.17509/ijal.v7i1.6877

Francis, G., Hunston, S., \& Manning, E. (1996). Collins COBUILD grammar patterns 1: Verbs. London: HarperCollins.

Halliday, M. A. K. (1985). An introduction to functional grammar. London: Edward Arnold.

Halliday, M. A. K., \& Martin, J. R. (1993). Writing science: Literacy and discursive power. London: The Falmer Press.

Halliday, M., Matthiessen, C. M. (2014). An introduction to functional grammar $\left(4^{\text {th }}\right.$ Edition $)$. London: Routledge.

Harwood, N. (2009). An interview-based study of the functions of citations in academic writing across two disciplines. Journal of Pragmatics, 41(3), $497-$ 518. doi: 10.1016/j.pragma.2008.06.001.

Hewings, A., Lillis, T., \& Vladimirou, D. (2010). Who's citing whose writings? A corpus based study of citations as interpersonal resource in English medium national and English medium international journals. Journal of English for
Academic Purposes, 9(2), 102-115. doi: 10.1016/j.jeap.2010.02.005.

Hu, G., \& Wang, G. (2014). Disciplinary and ethnolinguistic influences on citation in research articles. Journal of English for Academic Purposes, 14, 14-28. doi: 10.1016/j.jeap.2013.11.001

Hyland, K. (1999). Academic attribution: citation and the construction of disciplinary knowledge. Journal of Applied Linguistics, 20(3), 341-367. doi: 10.1093/applin/20.3.341

Hyland, K. (2006). English for academic purposes: an advanced resource book. Abingdon: Routledge.

Hyland, K. (2017). English in the disciplines: Arguments for specificity. ESP Today, 5(1), 5-23. doi: 10.18485/esptoday.2017.5.1.1

Jalilifar, A., \& Dabbi, R. (2012). Citation in applied linguistics: Analysis of introduction sections of Iranian master theses. Linguistik online, 57(7), 91104. doi: 10.13092/lo.57.252

Jalilifar, A., White, P., \& Malekizadeh, N. (2017). Exploring nominalization in scientific textbooks: A cross-disciplinary study of hard and soft sciences. International Journal of English Studies, 17(2), 1-20. doi: 10.6018/ijes/2017/2/272781

Jomaa, N. J., \& Bidin, S. J. (2016). Roles of the cited author in citations of the literature review by EFL postgraduates. International Journal of Applied Linguistics and English Literature, 5(7), 213-225. doi: 10.7575/aiac.ijalel.v.5n.7p.213

Jomaa, N. J., \& Bidin, S. J. (2017). Perspectives of EFL doctoral students on challenges of citations in academic writing. Malaysian Journal of Learning and Instruction, 14(2), 177-209. doi: 10.32890/mjli2017.14.2.7

Jomaa, N. J., \& Bidin, S. J. (2019). Reporting and Quoting: Functional Analyses of Logico-Semantic Relations of Clause Complex Citations. $3 L$ : The Southeast Asian Journal of English Language Studies, 25(1), 158-178. doi: 10.17576/3L-20192501-12

Law, L., Ting, S. H., \& Jerome, C. (2013). Cognitive dissonance in dealing with plagiarism in academic writing. The 9th International Conference on Cognitive Science: Procedia - Social and Behavioral Sciences, 97(6), 278-284. doi: 10.1016/j.sbspro.2013.10.234

Manan, N. A., \& Noor, N. M. (2014). Analysis of reporting verbs in master's theses. Procedia Social and Behavioral Sciences, 134, 140-145. doi: 10.1016/j.sbspro.2014.04.232

Mansourizadeh, K., \& Ahmad, U. K. (2011). Citation practices among non-native expert and novice scientific writers. Journal of English for Academic Purposes, 10(3), 152-161. doi: 10.1016/j.jeap.2011.03.004

Monreal, C. S., \& Salom, L. G. (2011). A crosslanguage study on citation practice in $\mathrm{PhD}$ theses. International Journal of English 
Studies, 11(2), 53-75. doi:

10.6018/ijes/2011/2/149641

Nguyen, T. T. L., \& Pramoolsook, I. (2016). Reporting verbs in literature review chapters of TESOL Master's theses written by Vietnamese postgraduates. GEMA Online Journal of Language Studies, 16(2), 17-32. doi: 10.17576/gema-20161602-02

Okamura, A. (2008). Citation forms in scientific texts: similarities and differences in L1 and L2 professional writing. Nordic Journal of English Studies, 7(3), 61-81.

Park, H., \& Nam, D. (2017). Corpus linguistic research trends from 1997 to 2016: A co-citation analysis. Linguistic Research, 34(3), 427-457. doi: 10.17250/khisli.34.3.201712.008

Pecorari, D. (2008). Academic writing and plagiarism: A linguistic analysis. London: Continuum.

Petrić, B., \& Harwood, N. (2013). Task requirements, task representation, and self-reported citation functions: An exploratory study of a successful L2 student's writing. Journal of English for Academic Purposes, 12(2), 110-124. doi: 10.1016/j.jeap.2013.01.002

Polio, C., \& Shi, L. (2012). Perceptions and beliefs about textual appropriation and source use in second language writing. Journal of Second Language Writing, 21(2), 95-101. doi: 10.1016/j.jslw.2012.03.001

Rabab'ah, G., \& Al-Marshadi, A. (2013). Integrative vs. non-integrative citations among native and nonnative English Writers. International Education Studies, 6(7), 78-87. doi: 10.5539/ies.v6n7p7

Rowley-Jolivet, E., \& Carter-Thomas, S. (2014). Citation practices of expert French writers of English: issues of attribution and stance. In A. Lyda and K. Warchal (Eds.), Occupying niches: Interculturality, cross-culturality and aculturality in academic research (pp.17-34). London: Springer International Publishing.
Samraj, B. (2013). Form and function of citations in discussion sections of master's theses and research articles. Journal of English for Academic Purposes, 12(4), 299-310. doi: 10.1016/j.jeap.2013.09.001

Shi, L. (2012). Rewriting and paraphrasing source texts in second language writing. Journal of Second Language Writing, 21(2), 134-148. doi: 10.1016/j.jslw.2012.03.003

Swales, J. M. (1990). Genre analysis. Cambridge: Cambridge University Press.

Swales, J. M. (2014). Variation in citational practice in a corpus of student biology papers: From parenthetical plonking to intertextual storytelling. Written Communication, 31(1), 118-141. doi: 10.1177/0741088313515166

Thompson, P. (2001). A pedagogically-motivated corpus-based examination of PhD theses: macrostructure, citation practices and use of modal verbs (Unpublished $\mathrm{PhD}$ thesis). School of Linguistics and Applied Language Studies, The University of Reading, UK.

Thompson, P. (2002). Manifesting intertextuality in the $\mathrm{PhD}$ theses. Revista Canaria De Estudios Ingleses. 44, 97-114.

Thomas, S., \& Hawes, T. P. (1994). Reporting verbs in medical journal articles. English for Specific Purposes, 13(2), 129-148. doi: 10.1016/08894906(94)90012-4

Thompson, G., \& Ye, Y. (1991). Evaluation in the reporting verbs used in academic papers. Applied Linguistics, 12(4), 365-382. doi: 10.1093/applin/12.4.365

Thompson, P., \& Tribble, C. (2001). Looking at citations: Using corpora in English for academic purposes. Language Learning and Technology, 5(3), 91-105.

Yang, L. (2013). Evaluative functions of reporting evidential in English research articles of Applied Linguistics. Open Journal of Modern Linguistics, 3(2), 119-126. doi: 10.4236/ojml.2013.32016 